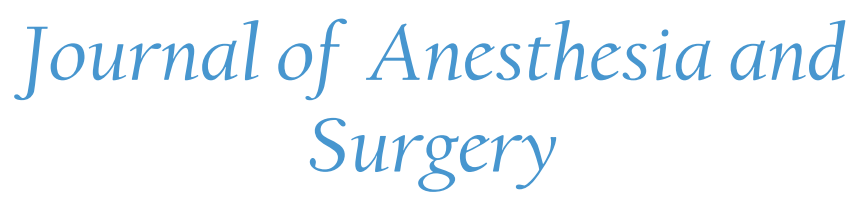

\title{
Anesthetic Challenges and Management of Maxillofacial Trauma
}

\author{
Sweta Singh, Shailendra Kumar, Kaushal Kumar, Babita Gupta* \\ Department of Anesthesiology and Intensive Care, JPNATC, All India Institute of Medical Sciences, New Delhi, India
}

"Corresponding author: Babita Gupta, Department of Anesthesiology and Intensive Care, JPNATC, All India Institute of Medical Sciences, New Delhi, Inida, Tel: 09-9868397815; E-mail: drbabitagupta@hotmail.com

\begin{abstract}
Management of Maxillofacial trauma is a challenging task for an anaesthesiologist. It requires a prompt and skillful response from the anaesthesia team. Bilateral parasymphsial fracture, condylar fracture, fracture of zygoma, flattening of face, moderate bleeding and derranged occlusion are the main cautionary pointers of difficult airway. Emergency airway management should be done by a team led by an anaesthesiologist. A difficult airway cart along with resuscitation trolley should be ready. Plan A should be direct laryngoscopy and manual in line stabilization. Video laryngoscope if available should be preferred. Plan B must include fiberoptic, optical and lighted stylets and airway rescue supraglottic devices. Surgical access should be used as backup plan C. Elective management for definitive surgery should be based on specific maxillofacial trauma, surgical approach, associated inflammation and need of prolonged mechanical ventilation in postoperative period.
\end{abstract}

Received date: August 2, 2017

Accepted date: November 27, 2017 Published date: December 2, 2017

Citation: Gupta, B., et al. Anesthetic Challenges and Management of Maxillofacial Trauma. (2017) J Anesth Surg 4(2): 134- 140 .

DOI: $10.15436 / 2377-1364.17 .082$

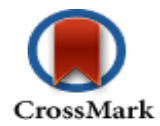

\section{Introduction}

Trauma means an injury caused to the body. Trauma in the modern world has huge impact on the society as it affects predominantly productive age group, economically causes overburden of $\$ 500$ billion annually and have high morbidity and mortality ${ }^{[1,2]}$. Amongst all, road traffic accident is the leading cause of trauma and it constitutes $25 \%$ of overall mortality inflicted by trauma ${ }^{[2]}$. Road accident alone kills 382 persons in India every day i.e 1682 times more than the terrorism. It is due to such an impact that "World trauma day" is celebrated on $17^{\text {th }}$ October and the decade 2011 - 20 is officially proclaimed as decade of action for road safety by United Nations (UN) general assembly. Road accidents are the main culprit of maxillofacial injury apart from assault, fall from height, sports injury and civilian warfare ${ }^{[3]}$.

Maxillofacial injury is generally accompanied with other associated injuries, which require coordinated approach between emergency physician, maxillofacial surgeon, anesthesiologist, orthopedician, opthalmologists, neurosurgeons and otolaryngology specialists ${ }^{[4-6]}$. The patient with maxillofacial injury poses a unique challenge to anesthesiologist starting from emergency department for securing the airway to definitive surgical correction in the operation theatre. These patients present in emergency room with complex and frightening appearance and threatened airway scenario which is complicated further by distorted facial anatomy, associated cervical and head injury, full stomach, presence of blood, secretions, vomitus, foreign objects and avulsed teeth and edema ${ }^{[7]}$. Emergency management of a trauma patient with maxillofacial injury starts with airway maintenance with cervical spine control ${ }^{[2]}$. As per the Advanced trauma life support (ATLS ${ }^{\circledR}$ ) loss of an airway kills more quickly than does the loss of the ability to breathe or circulatory problems ${ }^{[8]}$. Moreover, acute airway obstruction can cause hypoxic brain injury and death, so airway maintenance is of paramount importance in maxillofacial trauma ${ }^{[9]}$. Emergency surgery is rarely required; only in presence of airway compromise and/or severe hemorrhage ${ }^{[10]}$. Definitive surgery is generally planned 
after the patient has been stabilised, airway has been secured and bleeding is controlled ${ }^{[9]}$. Patient with facial trauma generally die from associated injuries ${ }^{[11,12]}$. In this review, we will discuss relevant anatomy, etiology, pathophysiology and management of patient with maxillofacial injury in the from emergency department and operating room.

\section{Anatomy}

The face is divided into equal thirds ${ }^{[13-15]}$

- The upper face, from the hairline to the glabella. Fractures in this region involve the frontal bone and frontal sinus.

- The midface consists of nine bones from the glabella to the base of the columella. Fractures in this region involve the maxilla, nasal bones, nasoethmoidal complex (NOE), zygomaticomaxillary complex (ZMC), and orbital floor.

- The lower face, from the base of the columella to the soft tissue menton. The lower third is subdivided in an upper third from the columella base to the lip commissure and two lower thirds from the lower lip to menton. Fractures in this region involve the dentoalveolar segments and the mandible.

Maxillary fractures: These are classified as Le Fort I, II, or III LeFort I fracture is a horizontal maxillary fracture across the inferior aspect of the maxilla separating the alveolar process containing the maxillary teeth and hard palate from the rest of the maxilla. The fracture extends through the lower third of the septum and includes the medial and lateral maxillary sinus walls extending into the palatine bones and pterygoid plates.

LeFort II fracture is a pyramidal fracture starting at the nasal bone and extending through the ethmoid and lacrimal bones; downward through the zygomaticomaxillary suture; continuing posteriorly and laterally through the maxilla, below the zygoma; and into the pterygoid plates.

LeFort III fracture or craniofacial disjunction is a separation of all of the facial bones from the cranial base with simultaneous fracture of the zygoma, maxilla, and nasal bones. The fracture line extends posterolaterally through ethmoid bones, orbits, and pterygomaxillary suture into the sphenopalatine fossa.

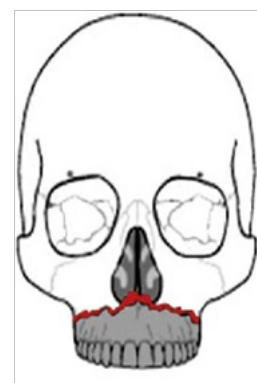

Type I

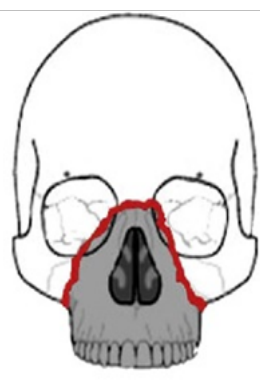

Type II

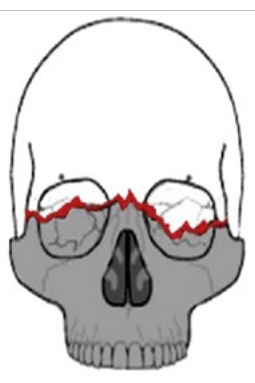

Type III
Lefort fracture Type I-III

\section{Etiology}

Motor vehicle accidents (MVA) are the most common cause of facial injury in the developing world ${ }^{[16,17]}$. According to National crime record bureau (NCRB) about 1.37 million people died in road accidents in India in 2013 and 20 million were hospitalized due to injuries. Other common causes are assault, fall, sports injury and industrial accidents. Maxillofacial injuries have male preponderance and it may be related to drug and alcohol intoxication ${ }^{[16,18,19]}$. MVA mostly causes fracture of maxilla and mandible and lead to airway compromise ${ }^{[20]}$. Assaults are the main cause of facial injury in developed world followed by $\mathrm{MVA}^{[18]}$. It commonly produce fractures of nasal bones, mandible and zygoma ${ }^{[16,19,21]}$.

\section{Pathophysiology}

The force generated by dispersion of kinetic energy due to sudden deceleration of moving object leads to injury. The force can be high impact if it is more than 50 times the force of gravity and low impact if less than 50 times the force of gravity ${ }^{[20]}$. Nasal bones and zygoma require low impact force for damage whereas supraorbital rim, maxilla, mandible and frontal bone require high impact force for damage ${ }^{[20]}$.

\section{Classification and Anaesthetic challenges ${ }^{[20,22,23]}$ \\ Facial injuries are classified into upper face, mid face} and lower face fracture according to part of the face involved.

\section{Upper Face}

Frontal Bone and Sinuses: Common presenting features are facial pain, paraesthesia of supraorbital and supratrochlear nerve, crepitus of supraorbital rim, subcutaneous emphysema, forehead depression and CSF leak. Anaesthetic issues relate to high incidence of associated intracranial haematoma, CSF leak, pneumocephalus leading to altered consciousness. Associated basal skull fractures precluding nasogastric tube insertion, packing and nasotracheal intubation.

\section{Mid-Face}

Orbital floor fracture: Periorbital edema, crepitus, echymosis are present along with paresthesia of lateral side of nose, upper lip and maxillary gingiva, lateral and upward gaze dysfunction and diplopia. This may also be associated with basal skull fracture and associated complications.

Nasal bone fracture: Most common facial fracture due to central location and prominence. Common presenting features are swollen and tender nose, epistaxis and crepitus. Bleeding and difficult mask ventilation are the main concerns of an anaesthesiologist.

Nasoethmoid fracture: Commonly presents with telecanthus, epistaxis, CSF rhinorrhea and epiphora. Bleeding, CSF leak, subcutaneos emphysema is the main airway isues in this injury. Zygomatic arch fracture: Pain and limitation of movement of mandible along with palpable defect over the area are common presentation of fracture of zygomatic arch. Depressed fractures of the zygomatic arch cause mechanical interference in the movement of coronoid process. Therefore, fractures of Zygoma in an X ray or CT scan should alert the anaesthesiologist of possible mechanical difficulty in mouth opening instead of trismus and pain.

Zygomaticomaxillary complex fracture: Flame sign seen due to disruption of lateral canthal tendon. Paraesthesia, diplopia, trismus are the other common presentation of this fracture. Possibility of mechanical difficulty in mouth opening, subcutaneous emphysema, posterior displacement of fractured maxillae lead- 
ing to nasopharyngeal obstruction are the main airway concerns.

\section{Maxilla fracture}

Lefort I- Facial edema and mobility of hard palate, maxillary alveolus and teeth are seen. Derranged occlusion, loose dentition, bleeding and difficult mask ventilation are the major concerns of an anaesthesiologist.

Lefort II- Facial edema, telecanthus, subconjuctival haemorrhage, mobility of maxilla at nasofrontal suture, epistaxis and CSF rhinorrhea are the clinical features. The airway concerns are similar to midfacial structures.

Lefort III- They present with massive facial edema with rounding, elongation and flattening. Movement of all facial bones in relation to cranial base with manipulation of teeth and hard palate are seen. They also present with epistaxis and CSF rhinorrhea. Flattening of face corresponds to posterior displacement of maxilla on to nasopharynx. Fractured or exfoliated teeth, bone fragments, vomitus, blood, and secretions may block the airway anywhere along the oropharynx and larynx.

Mandibular fracture: Pain anterior to meatus is seen. They also present with painful jaw movement, malocclusion of teeth and inability to open the mouth and bite down hard. Mobility and crepitus can be elicited along the symphysis, angles of mandible, or body. An anterior open bite can occur with bilateral condylar or angle fractures. Condylar fractures can lead to mechanical interference with jaw movement. A bilateral fracture of the anterior mandible may cause the fractured symphysis and the tongue to slide posteriorly and block the oropharynx in the supine patient.

Panfacial: It must be composed of 3 of 4 possible facial units. It generally presents with signs and symptoms of combination of the various fracture of the face discussed above and most challnging for an anaesthesiologist.

\section{Management of Maxillofacial Injury \\ Emergency Management}

As per the ATLS $^{\circledR}$ protocol, emergency management starts with securing the airway with cervical spine control in life threatening conditions. Most often error in airway management lead to increased morbidity and mortality ${ }^{[24,25]}$. Grien et al found that $16 \%$ of inpatient death were due to inability to secure an airway ${ }^{[25]}$.

Airway assessment: It is done as quickly as possible to prevent hypoxia and hypoxemia. Patient has to be evaluated for loss of consciousness, loss of spontaneous breathing and severity and extent of injury ${ }^{[26,27]}$. A quick assessment of airway is done by LEMON assessment. It consists of Look externally to detect difficult airway predictors, such as short neck, Evaluate mouth opening and thyromental distance, Mallampati class, Obstruction of the upper airway and Neck mobility ${ }^{[27,28]}$. Apart from this additional predictors for difficult airway are taken into account like presence of blood or vomitus in airway, cervical spine immobility, airway oedema and obesity. Gaither et al in their study cited obesity as independent risk factor for difficult intubation ${ }^{[29]}$.

\section{Complexity of the situation}

Distorted anatomy: These patients present with difficult mask ventilation and intubation due to distorted anatomy of the face caused by severe injury ${ }^{[30,31]}$

Full stomach: The dictum is "all the trauma patients should be considered as full stomach"[32-36]. Nasogastric tube should be placed with caution and better be avoided in upper facial and lefort II \& III fractures. Another approach for prevention of aspiration for full stomach patient is rapid sequence induction (RSI) with sellick's maneuver ${ }^{[35]}$. The role of this approach, though widely used, in term of effectiveness and safety is questionable and moreover laryngeal view may be worsened ${ }^{[32,37]}$. Thus, its use should be on individual patient to patient basis.

Cervical spine injury: A patient having injury above the clavicle should be considered to have associated cervical spine injury until proved otherwise by imaging ${ }^{[38-40]}$. Around $6 \%$ of patients with maxillofacial injury have associated cervical spine injury ${ }^{[41-43]}$. Cervical spine movement during intubation is prevented by manual inline stabilization by an assistant throughout the procedure $^{[44]}$. Use of McCoy laryngoscope, bougies and videolaryngoscope have been studied and found to have less cervical movement during intubation and should be preferred ${ }^{[30,47-49]}$.

Maxillofacial bleeding: Severe life threatening bleeding can occur due to isolated facial trauma but shock from hemorrhage is uncommon ${ }^{[50-52]}$. Emergency surgery is generally not required until life threatening hemorrhage is present. Blood substitutes, packing, ligation and sometimes if uncontrolled hemorrhage is present, arterial embolization is the mainstay of treatment ${ }^{[33]}$.

Laryngotracheal injury: Around 96\% patients of layngotracheal trauma have associated maxillofacial injury and most are related with difficult airway ${ }^{[54]}$.

Emergency situation: During emergency, complications of intubation like hypoxemia, dysarrhythmias, esophageal intubation and cardiac arrest are increased upto $20 \%$ and this complication are mainly due to repeated attempts, laryngoscopy without muscle relaxatation and lack of experience of operator ${ }^{[55,56]}$.

Personal experience: Time is vital in emergency airway management but ironically most of the intubations are done by nonanesthesiologists in emergency situations ${ }^{[59]}$. In study by Walls et al only $3 \%$ of intubation were done by anaesthesiologists $^{[57]}$.

\section{Mode of airway control}

Difficult airway trolley should be kept ready which contain laryngoscope of various type and size, video laryngoscope, bougies, laryngeal mask airway (LMA) of various types and size, flexible fiberoptic bronchoscope (FOB), optical stylet and various lighted stylet, surgical device for cricothyroidotomy and tracheostomy ${ }^{[58]}$. No single technique of intubation will be applicable for all traumatic facial injuries. Type of injury, time of surgery, and the surgical approach will be the deciding factors for mode of intubation ${ }^{[17]}$. The airway should be reassessed periodically to rule out delayed airway compromise that is due to airway edema and hematoma.

Direct laryngoscopy and orotracheal intubation with manual in-line stabilization of neck: If there is no anticipated difficult airway and mouth opening is adequate, this is the most pre- 
ferred and easily available technique in emergency. An assistant will stabilize the cervical spine and the anaesthesiologist or the physician will intubate the patient with direct laryngoscopy with minimal extension force.

Video laryngoscopic guided orotracheal intubation: c-MAC videolaryngoscope, glidescope and the newer handheld videolaryngoscope have been shown to decrease cervical movement during intubation and recently have become the technique of choice in patients with maxillofacial trauma with mild bleeding and more than $2 \mathrm{~cm}$ mouth opening.

Blind Nasotracheal intubation: In patients with severe mechanical restriction to mouth opening, Blind nasal intubation guided by capnography is employed in emergency.

FOB guided Nasotracheal intubation: Fiberoptic guided nasotracheal intubation is the safest way of airway management in these patients with severe restriction in mouth opening. However, the usefulness of FOB may be jeopardised by untrained personnel and presence of blood and secretions in the airway ${ }^{[30]}$.

Video laryngoscopic guided nasotracheal intubation: Newer videolaryngoscope have slim blades and that can be introduced even if the mouth opening is $1.5 \mathrm{~cm}$. Though manipulations with magill forceps is not possible with this mouth opening, the view shown by the laryngoscope can help in guiding the head maneuvres during blind nasal intubation.

Optical/ Lighted stylet guided nasotracheal intubation: Optical and lighted stylets can help in guiding the nasaly introduced endotracheal tube into the trachea similar to the videolaryngoscope. Lighted stylets can be used in moderate to severe oral bleeding too. When inside the trachea, the light will be visible from the skin in midline of neck.

Airway Rescue devices (Intubating LMA, Combitube): Combitube in the prehospital settings is inserted blindly into the oropharynx in facial trauma patients but it can cause complications like false track formation, oedema, vocal cord injury, tracheal injury and esophageal injury ${ }^{[59]}$. LMA act as a bridging device for ventilation in difficult airway scenario and most useful in "cannot intubate and cannot ventilate" situation ${ }^{[30-31]}$ Intubating LMA can further be used to guide intubation through it.

Cricothyroidotomy and manual jet ventilation: Needle cricothyroidotomy can be used as a life-saving procedure to salvage a difficult airway scenario ${ }^{[60]}$. Following Needle cricothyroidotomy, the cannulae is connected to manual jet ventilation device for oxygenation and buying time for a definitive airway. Surgical cricothyroidotomy is the choice for emergency airway control ${ }^{[61]}$.

Emergency tracheostomy: Tracheostomy in emergency condition is not advisable as it is time consuming.61 But it is the measure of last resort in any airway emergency especially in short and thick neck patients in whom cricothyroid membrane is not appreciated.

\section{Elective Management}

Elective management is surgical reduction and immo- bilization (Intermaxillary fixation) ${ }^{[27]}$. Main concern for elective surgery is airway control and blood loss. Proper preanaesthetic check up is done for evaluation of multisystem organ and airway. There should be discussion with surgeon regarding route of intubation, type and size of the tracheal tube and alternative method of intubation ${ }^{[64]}$.

\section{Anaesthetic technique}

The risk of airway related complications are there even in elective airway control and this amount to $67 \%, 15 \%$, $12 \%$ and $5 \%$ during induction, intraoperatively, extubation and during recovery respectively ${ }^{[65]}$. The anaesthetic plan should be based on the difficulty of airway.

Conventional induction: If there is no anticipated difficulty in airway assessment, then routine direct laryngoscopy with manual in-line stabilization is the most commonly employed technique if cervical spine injury is present or not ruled out. However, Videolaryngoscopy should be preferred in these case owing to less cervical movement during intubation. It can also be a Plan B along with airway rescue supraglottic devices.

Rapid sequence induction: If there is difficulty in mask ventilation but there is no anticipated difficulty in laryngoscopy and intubation, then modified rapid sequence induction with short acting muscle relaxant and direct laryngoscopy and intubation is preferred. In any case, difficult airway cart with plan B \& C should be ready.

Awake fiberoptic technique: In case of anticipated difficult airway, Awake fiberoptic intubation after adequate airway preparation with local anaesthesia or spray as you go technique. It is the safest technique in patients without any active bleeding.

Tracheostomy under local anaesthesia: In patients with gross distortion of airway, anterior neck injury requiring multiple surgeries and prolonged intubation, Tracheostomy under local anaesthesia followed by general anaesthesia is the safest technique.

\section{Airway control technique}

It should be such that it should not interfere with surgery. Various method of airway control are available and merits and demerits are listed in table $1^{[66]}$.

Oral/ Naotracheal Intubation: Direct laryngoscopy with orotracheal intubation with cervical spine control is commonly used but some surgeons prefer unobstructed view and they ask for nasal intubation. It is found to be safe in cases of skull base fracture contrary to common belief ${ }^{[67-69]}$. Rhee $\mathrm{K} \mathrm{J}$ et al in their study found no increase in complication rate in skull base fracture when nasotracheal intubation is used ${ }^{[70]}$. Glidescope is used for difficult intubation with minimal neck movement ${ }^{[47]}$. In difficult airway, awake flexible fiberoptic guided intubation via oral or nasal route under local anaesthesia is safe option ${ }^{[71]}$.

Retromolar intubation: It is done with slightly smaller tube which is pushed into retromolar space and is secured. This is non invasive method which is useful in difficult airway scenario where nasal intubation is also contraindicated ${ }^{[72]}$. 
Submental intubation: This approach for intubation is done through $2 \mathrm{~cm}$ incision made halfway between chin and angle of mandible and blunt dissection is performed to the oral floor. Surgical tunnel is made through dissection of superficial fascia, platysma and deep fascia. The tube is then pulled through this access using rotational movements of spiral reinforced armoured endotracheal tube and then it is connected to anaesthesia machine ventilator. This is mainly used to avoid tracheostomy and where nasal intubation are contraindicated. This is converted to orotracheal intubation before extubation. Submental intubation is contraindicated in patients requiring long term ventilation ${ }^{[73]}$.

Submandibular intubation: It is just a modification of submental intubation where incision is posterior to submandibular region to avoid injury to the salivary gland ${ }^{[74]}$.

Surgical airway: Tracheostomy is a safe elective option when extensive facial deformity is present distorting the airway and in patients requiring long term elective ventilation ${ }^{[74]}$.

Table 1: Advantages and disadvantages of various airway management techniques used in maxillofacial trauma for Elective surgery.

\begin{tabular}{|l|l|l|}
\hline $\begin{array}{l}\text { Airway } \\
\text { management } \\
\text { technique }\end{array}$ & Advantages & Disadvantages \\
\hline $\begin{array}{l}\text { Oral } \\
\text { endotracheal } \\
\text { intubation }\end{array}$ & $\begin{array}{l}\text { Quickest technique of } \\
\text { securing airway } \\
\text { Can be employed for nasal } \\
\text { fractures. }\end{array}$ & $\begin{array}{l}\text { Cannot be employed } \\
\text { for Maxillo-mandibu- } \\
\text { lar fracture fixation }\end{array}$ \\
\hline $\begin{array}{l}\text { Fiberoptic } \\
\text { guided nasal } \\
\text { endotracheal } \\
\text { intubation }\end{array}$ & $\begin{array}{l}\text { Non invasive } \\
\text { Real time imagining of } \\
\text { airway } \\
\text { Can be employed for } \\
\text { Maxillo-mandibular frac- } \\
\text { ture fixation }\end{array}$ & $\begin{array}{l}\text { Cannot be employed } \\
\text { for nasal surgery } \\
\text { Risk of nasal bleeding } \\
\text { Contraindicated in } \\
\text { skull base fracture }\end{array}$ \\
\hline $\begin{array}{l}\text { Retromolar } \\
\text { endotracheal } \\
\text { intubation }\end{array}$ & $\begin{array}{l}\text { Non invasive } \\
\text { Simple } \\
\text { Can be employed for both } \\
\text { nasal and Maxillo-man- } \\
\text { dibular fracture fixation }\end{array}$ & $\begin{array}{l}\text { Endotracheal tube in } \\
\text { operating field } \\
\text { Risk of buccal nerve } \\
\text { palsy }\end{array}$ \\
\hline $\begin{array}{l}\text { Submental } \\
\text { intubation }\end{array}$ & $\begin{array}{l}\text { Can be employed for both } \\
\text { nasal and Maxillo-man- } \\
\text { dibular fracture fixation } \\
\text { Complete occlusion } \\
\text { Operating field is clear }\end{array}$ & $\begin{array}{l}\text { Invasive } \\
\text { Maximum duration of } \\
\text { use for 24-48 hours } \\
\text { Risk of infection } \\
\text { Risk of salivary fistula }\end{array}$ \\
\hline Tracheostomy & $\begin{array}{l}\text { Definitive airway } \\
\text { Better pulmonary toileting } \\
\text { Long term ventilation } \\
\text { possible } \\
\text { Better tolerated by the } \\
\text { patient }\end{array}$ & $\begin{array}{l}\text { Invasive } \\
\text { Complications of tra- } \\
\text { cheostomy procedure } \\
\text { Post tracheostomy } \\
\text { care } \\
\text { Risk of tracheal } \\
\text { stenosis }\end{array}$ \\
\hline
\end{tabular}

Mostly these types of patients are difficult airway candidates, so anaesthetic agents which results in early awakening and early return of airway reflexes are used perioperatively. These patients are considered at high risk extubation as per extubation guidelines ${ }^{[75]}$. Patient should not be extubated till patient is fully conscious, return of reflexes and obeying commands. PONV prophylaxis is given before extubation. Effective pain control can be achieved through patient controlled analgesia ${ }^{[76]}$.
The patients should be monitored in post anaesthesia care unit or intensive care unit and wire cutters should be kept ready if any emergency airway intervention is required.

\section{Conclusion}

Maxillofacial trauma patient management is unique and complex which starts from emergency to definitive surgical correction. Multidisciplinary approach is required for management of trauma patient. Airway control is the prime concern and airway is secured immediately with various techniques available. Direct laryngoscopy and orotracheal intubation with manual in line stabilization is still the technique of choice However; Videolaryngoscopy should be preferred to minimize cervical movement. Airway rescue supraglottic airway devices, fiberoptic and lighted stylets should be included in plan B of airway management. Surgical approach should be reserved as a last option.

\section{References}

1. Saraswat, V. Airway Management in Maxillofacial Trauma: A Retrospective Review of 127 Cases. (2008) Indian J Anaesth 52: 311-316. Pubmed | Crossref $\mid$ Others

2. American College of Surgeons Committee on Trauma, et al. Advanced trauma life support (ATLS $®$ ): the ninth edition. (2013) J Trauma Acute Care Surg 74(5): 1363-1366.

Pubmed $\mid$ Crossref $\mid$ Others

3. Telfer, M.R., Jones, G.M., Shepherd, J.P. Trends in the aetiology of maxillofacial fractures in the United Kingdom (1977-1987). (1991) Br J Oral Maxillofac Surg 29(4): 250-255.

Pubmed | Crossref | Others

4. Rosen, P., Barkin, R., Rosen, P., et al. Emergency Medicine Concepts and Clinical Practice. 5th ed. St. Louis. (2002) Mo: Mosby-Year Book 315-329.

Pubmed $\mid$ Crossref $\mid$ Others

5. Tintinalli, J.E., Kelen, G.D., Stapczynski, J.S. Maxillofacial trauma, Emergency Medicine: A Comprehensive Study Guide. 6th edition (2004) New York, NY McGraw-Hill 1583-1589.

Pubmed $\mid$ Crossref $\mid$ Others

6. Delpachitra, S.N., Rahmel, B.B. Orbital fractures in the emergency department: a review of early assessment and management. (2015) Emerg Med J 33(10): 727-731.

Pubmed | Crossref | Others

7. Cicala, R.S., Kudsk, K.A., Butts, A., et al. Initial evaluation and management of upper airway injuries in trauma patients. (1991) J Clin Anesth 3(2): 91-98.

Pubmed | Crossref | Others

8. Walls, R.M. Management of the difficult airway in the trauma patient. (1988) Emerg Med Clin North Am 16(1): 45-61.

Pubmed | Crossref | Others

9. Manson, P.N. Facial Fractures In Plastic Surgery. The head and neck Part 2, Mathes (ed) 2nd edition. (2006) Saunders Elsevier Philadelphia 77.

\section{Pubmed $\mid$ Crossref $\mid$ Others}

10. Sood, J. Maxillofacial and Upper Airway Injuries Anaesthetic Impact. (2008) Indian Journal of Anaesthesia 52Suppl (5):688-698.

Pubmed $\mid$ Crossref $\mid$ Others

11. Thaller, S.R., Beal, S.L. Maxillofacial trauma: A potentially fatal injury. (1991) Ann Plast Surg 27(3): 281-283.

Pubmed | Crossref | Others

12. David, D.J., Simpson, D.A. Craniomaxillofacial Trauma. (1995)

Churchill Livingstone New York.

Pubmed $\mid$ Crossref $\mid$ Others

13. Capan, L.M., Miller, S.M., Glickman, R. Management of Facial In- 
juries in Trauma Anaesthesia And Intensive Care. (1991) JB Lippincott Company 12: 385-305.

Pubmed $\mid$ Crossref $\mid$ Others

14. Shearer, V.E., Gardner, J., Murphy, M.T. Perioperative anesthetic management of maxillofacial trauma including ophthalmic injuries. (1999) Anesthesiology Clinics 17: 141-152.

Pubmed | Crossref | Others

15. Manson, P.N., Hoopes, J.E., Su, C.T. Structural pillars of the facial skeleton: an approach to the management of Le Fort fractures. (1980) Plast Reconstr Surg 66(1): 54-62.

Pubmed | Crossref | Others

16. Motamedi, M.H. An assessment of maxillofacial fractures: a 5 year study of 237 patients. (2003) J Oral Maxillofac Surg 61(1): 61-64.

Pubmed | Crossref | Others

17. Raval, C.B., Rashiduddin, M. Airway management in patients with maxillofacial trauma a retrospective study of 177 cases. (2011) Saudi J Anaesth 5(1): 9-14.

Pubmed | Crossref | Others

18. Curran, J.E. Anesthesia for facial trauma. (2005) Anesth Intensive Care Med 6(8): 258-262.

Pubmed | Crossref | Others

19. Chidzonga, M.M. Mandibular fractures, analysis of 541 cases. (1990) Cent Afr J Med 36(4): 97-103.

Pubmed $\mid$ Crossref $\mid$ Others

20. Adamo, A.K. Initial evaluation and management of maxillofacial injuries.

Pubmed $\mid$ Crossref $\mid$ Others

21. Skerman, J.H. Anaesthetic management of craniofacial trauma and trauma to the airway. (2002) The Middle East Journal of Emergency Medicine 2: 2.

Pubmed $\mid$ Crossref $\mid$ Others

22. Krohner, R.G. Anesthetic considerations and techniques for oral and maxillofacial surgery. (2003) Int Anesthesiol Clin 41(3): 67- 89.

Pubmed | Crossref $\mid$ Others

23. Hutchison, I., Lawlor, M., Skinner, D. ABC of major trauma. Major maxillofacial injuries. (1990) BMJ 301(6752): 595-599.

Pubmed | Crossref | Others

24. Garcia, A. Critical care issues in the early management of severe trauma. (2006) Surg Clin North Am 86(6): 1359-1387.

Pubmed | Crossref | Others

25. Gruen, R.L., Jurkovich, G.J., McIntyre, L.K., et al. Patterns of errors contributing to trauma mortality: lessons learned from 2594 deaths. (2006) Ann Surg 244(3): 371-378.

Pubmed | Crossref | Others

26. Peralta, R., Hurford, W.E. Airway trauma. (2000) International Anesthesiology Clinics 38(3): 111-127.

Pubmed $\mid$ Crossref $\mid$ Others

27. Robertson, C.G., Doucet, J.C. Helping anesthesiologists understand facial fractures. (2013) Oral Maxillofac Surg Clin North Am 25(4): 561-572.

Pubmed | Crossref | Others

28. Mayglothling, J., Duane, T.M., Gibbs, M., et al. Emergency tracheal intubation immediately following traumatic injury. Eastern association for the surgery of trauma practice management guideline. (2012) Journal of Trauma and Acute Care Surgery 73(5): S333-S340.

Pubmed $\mid$ Crossref $\mid$ Others

29. Gaither, J.B., Spaite, D.W., Stolz, U., et al. Prevalence of difficult airway predictors in cases of failed prehospital endotracheal intubation. (2014) Journal of Emergency Medicine 47(3): 294-300.

Pubmed $\mid$ Crossref $\mid$ Others

30. Perry, M., Morris, C. Advanced trauma life support (ATLS) and facial trauma: can one size fit all? Part 2: ATLS, maxillofacial injuries and airway management dilemmas. (2008) Int J Oral Maxillofac Surg 37(4): 309-320.

Pubmed | Crossref | Others
31. Krausz, A.A., El-Naaj, I.A., Barak, M. Maxillofacial trauma patient: coping with the difficult airway. (2009) World J Emerg Surg 4: 21. Pubmed $\mid$ Crossref $\mid$ Others

32. Ellis, D.Y., Harris, T., Zideman, D. Cricoid pressure in emergency department rapid sequence tracheal intubations: A risk-benefit analysis. (2007) Ann Emerg Med 50: 653-65.

Pubmed | Crossref | Others

33. Levitan, R.M., Kinkle, W.C., Levin, W.J., et al. Laryngeal view during laryngoscopy: A randomized trial comparing cricoid pressure, backward-upward-rightward pressure, and bimanual laryngoscopy. (2006) Ann Emerg Med 47(6): 548-555.

Pubmed | Crossref | Others

34. Noguchi, T., Koga, K., Shiga, Y., et al. The gum elastic bougie eases tracheal intubation while applying cricoid pressure compared to a stylet. (2003) Can J Anaesth 50(7): 712-717.

Pubmed | Crossref | Others

35. Haslam, N., Parker, L., Duggan, J.E. Effect of cricoid pressure on the view at laryngoscopy. (2005) Anaesthesia 60(1): 41-47.

Pubmed | Crossref | Others

36. Sellick, B.A. Cricoid pressure to control regurgitation of stomach contents during induction of anaesthesia. (1961) Lancet 278(7199): 404-406.

Pubmed | Crossref | Others

37. Bhatia, N., Bhagat, H., Sen, I. Cricoid pressure: where do we stand? (2014) Journal of Anaesthesiology Clinical Pharmacology 30(1): 3-6. Pubmed | Crossref | Others

38. Jamal, B.T., Diecidue, R., Qutub, A., et al. The pattern of combined maxillofacial and cervical spine fractures. (2009) Journal of Oral and Maxillofacial Surgery 67(3): 559-562.

Pubmed | Crossref $\mid$ Others

39. Rahman, S.A., Chandrasala, S. When to suspect head injury or cervical spine injury in maxillofacial trauma? (2014) Dental Research Journal 11(3): 336-344.

Pubmed | Crossref $\mid$ Other

40. Beirne, J.C., Butler, P.E., Brady, F.A. Cervical spine injuries in patients with facial fractures: a 1-year prospective study. (1995) Int J Oral Maxillofac Surg 24(1 Pt 1): 26-29.

Pubmed | Crossref | Others

41. Haug, R.H., Wible, R.T., Likavec, M.J., et al. Cervical spine fractures and maxillofacial trauma. (1991) J Oral Maxillofac Surg 49(7): 725-729.

Pubmed | Crossref | Others

42. Hackl, W., Hausberger, K., Sailer, R., et al. Prevalence of cervical spine injuries in patients with facial trauma. Oral Surg Oral Med Oral Pathol Oral Radiol Endod 92(4): 370-376.

Pubmed | Crossref | Others

43. Crosby, E.T. Airway management in adults after cervical spine trauma. (2006) Anesthesiology 104(6): 1293-1318.

Pubmed | Crossref | Others

44. Manoach, S., Paladino, L. Manual in-line stabilization for acute airway management of suspected cervical spine injury: historical review and current questions. (2007) Annals of EmergencyMedicine 509(3): 236-245.

Pubmed | Crossref | Others

45. Santoni, B.G., Hindman, B.J., Puttlitz, C.M., et al. Manual in-line stabilization increases pressures applied by the laryn-goscope blade during direct laryngoscopy and orotracheal intubation. (2009) Anesthesiology 110(1): 24-31.

Pubmed | Crossref | Others

46. Kill, C., Risse, J., Wallot, P., et al. Videolaryngoscopy with glidescope reduces cervical spine movement in patients with unsecured cervical spine. (2013) Journal of Emergency Medicine 44(4): 750-756.

Pubmed | Crossref | Others

47. Robitaille, A., Williams, S.R., Tremblay, M.H., et al. Cervical spine motion during tracheal intubation with manual in-line stabilization: di- 
rect laryngoscopy versus GlideScope videolaryngoscopy. (2008) Anesthe-sia and Analgesia 106(3): 935-941.

Pubmed | Crossref | Others

48. Bhardwaj, N., Jain, K., Rao, M., et al. Assessment of cervical spine movement during laryngoscopy with Macintosh and Truview laryngoscopes. (2013) Journal of Anaesthesiology ClinicalPharmacology 29(3): 308-312.

Pubmed | Crossref | Others

49. Gabbott, D.A. Laryngoscopy using the McCoy laryngoscope after application of a cervical collar. (1996) Anaesthesia 51(9): 812-814.

Pubmed | Crossref | Others

50. Laurent, S.C., de Melo, A.E., Alexander-Williams, J.M. The use of the McCoy laryn- goscope in patients with simulated cervical spine injuries. (1996) Anaesthesia 51(1): 74-75.

Pubmed | Crossref | Others

51. Thaller, S.R., Beal, S.L. Maxillofacial trauma: a potentially fatal injury. (1991) Annals of Plastic Surgery 27(3): 281-283.

Pubmed | Crossref $\mid$ Others

52. Harris, T., Rice, S., Watts, B., et al. The emergency control of traumatic maxillofacial haemorrhage. (2010) European Journal of Emergency Medicine 17(4): 230-233.

Pubmed | Crossref | Others

53. Ardekian, L., Samet, N., Shoshani, Y., et al. Life-threatening bleeding following maxillofacial trauma. (1993) J Craniomaxillofac Surg 21(8): 336-338.

Pubmed | Crossref | Others

54. Liu, W.H., Chen, Y.H., Hsieh, C.T., et al. Transarterial embolization in the management of life-threatening hemorrhage after maxillofacial trauma: a case report and review of literature. (2008) The American Journal of Emergency Medicine 26(4): 516.3-516.5.

Pubmed | Crossref | Others

55. Khanna, S., Dagum, A.B. A critical review of the literature and an evidence-based approach for life-threatening hemor-rhage in maxillofacial surgery. (2012) Annals of Plastic Surgery 69(4): 474-478.

Pubmed | Crossref | Others

56. Verschueren, D.S., Bell, R.B., Bagheri, S.C., et al. Management of laryngo-tracheal injuries associated with craniomaxillofacial trauma. (2006) J Oral Maxillofac Surg 64(2): 203-214.

Pubmed | Crossref | Others

57. Mort, T.C. Complications of emergency tracheal intubation: immediate airway-related consequences: part II. (2007) Journal of Intensive Care Medicine 22(4): 208-215.

Pubmed | Crossref $\mid$ Others

58. Mechlin, M.W., Hurford, W.E. Emergency tracheal intubation: techniques and outcomes. (2014) Respiratory Care 59(6): 881-894.

Pubmed | Crossref | Others

59. Walls, R.M., Brown III, C.A., Bair, A.E., et al. Emergency airway management: a multi-center report of 8937 Emergency Department intubations. (2011) Journal of Emergency Medicine 41(1): 347-354.

Pubmed | Crossref | Others

60. Kovacs, G., Law, J.A., Ross, J., et al. Acute airway management in the emergency department by non-anesthesiologists. (2004) Cana-dian Journal of Anesthesia 51(2): 174-180.

Pubmed | Crossref | Others

61. Vézina, M.C., Trépanier, C.A., Nicole, P.C., et al. Complications associated with the Esophageal-Tracheal Combitube in the pre-hospital setting. (2007) Can J Anaesth 54(2): 124-128.

Pubmed | Crossref | Others
62. Salvino, C.K., Dries, D., Gamelli, R., et al. Emergency cricothyroidotomy in trauma victims. (1993) J Trauma 34(4): 503-505.

Pubmed | Crossref $\mid$ Others

63. McLure, H.A., Dob, D.P., Mannan, M.M., et al. A laboratory comparison of two techniques of emergency percutaneous tracheostomy. (1997) Anaesthesia 52(12): 1199-1201.

Pubmed | Crossref | Others

64. Gotta, A.W. Maxillofacial trauma: Anesthetic consideration. (1987)

ASA Refresher Course 15:39.

Pubmed $\mid$ Crossref $\mid$ Others

65. Peterson, G.N., Domino, K.B., Caplan, R.A., et al. Management of the difficult airway: a closed claims analysis. (2005) Anesthesiology 103(1): 33-39.

Pubmed $\mid$ Crossref $\mid$ Others

66. Bikash, R., et al. Anaesthetic management of maxillofacial trauma. (2013) Trends in anaesthesia and critical care 3: 231-237.

Pubmed $\mid$ Crossref $\mid$ Others

67. Bähr, W., Stoll, P. Nasal intubation in the presence of frontobasal fractures: a retrospective study. (1992) J Oral Maxillofac Surg 50(5): $445 \mathrm{e} 7$.

Pubmed | Crossref | Others

68. Rosen, C.L., Wolfe, R.E., Chew, S.E., et al. Blind nasotracheal intubation in the presence of facial trauma. (1997) J Emerg Med 15(2): 141-5.

Pubmed | Crossref | Others

69. Bracken, C.A. Base of skull fractures and intubation: archaic medicine or sound rationale? (2001) J Trauma 50: 365-366.

Pubmed $\mid$ Crossref $\mid$ Others

70. Rhee, K.J., Muntz, C.B., Donald, P.J., et al. Does nasotracheal intubation increase complications in patients with skull base fractures? (1993) Ann Emerg Med 22: 1145-1147.

Pubmed | Crossref $\mid$ Others

71. Apfelbaum, J.L., Hagberg, C.A., Caplan, R.A., et al. Practice guidelines for management of the difficult airway: an updated report by the American Society of Anesthesiologists Task Force on Management of the Difficult Airway. (2013) Anesthesiology 118(2): 251-270.

Pubmed $\mid$ Crossref $\mid$ Others

72. Malhotra, N. Retromolar intubation-a simple alternative to submental intubation. (2006) Anaesthesia 61(5): 515-516.

Pubmed $\mid$ Crossref $\mid$ Others

73. Lima Jr, S.M., Asprino, L., Moreira, R.W., et al. A retrospective analysis of submental intubation in maxillofacial trauma patients. (2011) J Oral Maxillofac Surg 69(7): 2001-5.

Pubmed | Crossref | Others

74. Anwer, H.M., Zeitoun, I.M., Shehata, E.A. Submandibular approach for tracheal intubation in patients with panfacial fractures. (2007) $\mathrm{Br} \mathrm{J}$ Anaesth 98(6): 835- 40.

Pubmed | Crossref | Others

75. Popat, M., Mitchell, V., Dravid, R., et al. Difficult Airway Society Guidelines for the management of tracheal extubation. (2012) Anaesthesia 67(3): 318- 40.

Pubmed | Crossref | Others

76. Zuniga, J.R. Guidelines for anxiety control and pain management in oral and maxillofacial surgery. (2000) J Oral Maxillofac Surg 58(10 Suppl 2):4-7.

Pubmed | Crossref | Others
Ommega Online Publishers

Journal Title: Journal of Anesthesia and Surgery (JAS)

Journal Short Name: J Anesth Surg
Journal ISSN: 2377-1364

E-mail: anestheisa@ommegaonline.com

Website: www.ommegaonline.org 